\title{
Adjuvant I-131 Therapy Positive
}

National Cancer Institute

\section{Source}

National Cancer Institute. Adjuvant I-131 Therapy Positive. NCI Thesaurus. Code

C160216.

Adjuvant I-131 therapy was administered. 